\title{
EVALUATION OF LARYNGOTRACHEAL ALTERATIONS ASSOCIATED WITH INTUBATION
}

\author{
Jeevan Ramchandra Galagali' ${ }^{1}$ Rahul Naga², Arvind Kumar Gupta ${ }^{3}$ \\ ${ }_{1}^{1}$ Associate Professor, Department of Otolaryngology, Command Hospital, Pune. \\ ${ }^{2}$ Graded Specialist, Department of Otolaryngology, INHS Asvini Hospital, Mumbai. \\ ${ }^{3}$ Resident, Department of Otolaryngology, Command Hospital, Pune.
}

\section{ABSTRACT}

\section{BACKGROUND}

Laryngeal injuries following intubation have a reported incidence from 63 to $94 \%$ and permanent sequelae are reported to be about 10 to $22 \%$ in the world literature. While several studies assessing the laryngeal complications are available in Western populations, minimal data is available in the literature regarding Indian population.

\section{AIM}

The aim of this study is to evaluate laryngeal lesions in patients after prolonged intubation ( $>24 \mathrm{hrs}$.), to correlate these lesions with the variables involved in the process of intubation and to determine the risk factors.

\section{MATERIALS AND METHODS}

The study was undertaken at the ICU of a Tertiary Care Hospital. All patients extubated at the intensive care unit of our hospital after at least $24 \mathrm{hrs}$. of intubation were included in the study. Fibreoptic bronchoscopy was done on day of extubation, and weekly for 03 weeks.

\section{RESULTS}

100 patients were included in the study. Laryngeal abnormalities were seen in 88 patients on the day of extubation. At the end of third week after extubation, only 09 patients had abnormal laryngeal findings. A multivariate stepwise regression model showed that bigger tube size and longer duration of intubation was associated with higher incidence of laryngeal complications on the day of extubation. At the end of third week, laryngeal findings were influenced only by the duration of intubation and size of endotracheal tube.

\section{CONCLUSION}

Laryngeal alterations after extubation are directly associated with duration of intubation and size of endotracheal tube.

\section{KEYWORDS}

Intubation, Laryngotracheal Alterations.

HOW TO CITE THIS ARTICLE: Galagali JR, Naga R, Gupta AK. Evaluation of laryngotracheal alterations associated with intubation. J. Evolution Med. Dent. Sci. 2016;5(80):5980-5983, DOI: 10.14260/jemds/2016/1350

\section{INTRODUCTION}

Tracheal intubation is the placement of a flexible plastic tube into the trachea to maintain an open airway or to serve as a conduit through which to administer certain drugs. It is frequently performed in critically injured, ill or anesthetised patients to facilitate ventilation of the lungs. While the indications for intubation are varied, it is commonly used for ventilatory assistance, relief of upper airway obstruction and to aid in tracheobronchial toileting. With the advent of high volume low-pressure tubes, it is common for the patients to be ventilated through the endotracheal tube for up to 3 weeks. In endotracheal intubation, presence of pipes or nasotracheals in direct contact with the structures of the airways can provoke injuries of mucosal layer.

Financial or Other, Competing Interest: None.

Submission 01-05-2016, Peer Review 22-09-2016,

Acceptance 28-09-2016, Published 06-10-2016.

Corresponding Author:

Dr. Arvind Kumar Gupta,

Department of ENT,

Golden Jubilee Block,

AFMC,

Pune 411040.

E-mail: arvind.cnmc@gmail.com

DOI: $10.14260 /$ jemds $/ 2016 / 1350$

\section{(c) $(1)$}

These injuries are mainly of traumatic origin, due to drawn out intubations, use of pipes of great bore or due to raised pressure in the ballonet of probes.[1] Most complications of intubation become apparent only after extubation and may manifest in the early or late post-extubation period leading to the significant increase in short- and long-term morbidity.[2] For the otorhinolaryngologist, the earliest concerns revolve around the damage occurring in the larynx and trachea with the use of intubation. Study by Donelly demonstrated that there is pressure necrosis type of injury occurring at points of tissue tube interfacing. The mucosa here is extremely fragile and even the benign act of pulling a cotton swab along it causes loss of epithelium. The incidence of laryngeal complications has been evaluated in a number of studies with a wide variety of results. [3] Complications associated with tracheal intubation may occur in up to $40 \%$ of critically ill patients. Since practice in emergency airway management varies between intensive care units (ICUs) and countries, complication rates may also differ. Some complications have global incidence varying from $0 \%$ to $18 \% .{ }^{[4]}$ In one prospective study, it was found that acute injuries of larynx were present in $63 \%$ of patients who underwent orotracheal intubation and that they had been reversible in 30 days.[5]

Though, several studies assessed the laryngotracheal alterations, little information is available in Indian population. 
Therefore, we prospectively evaluated the laryngotracheal alterations in patients after intubation at the ICU of our Tertiary Care Hospital.

\section{AIM AND OBJECTIVES}

The aim of this study is to evaluate laryngeal lesions in patients after prolonged intubation ( $>24 \mathrm{hrs}$.), to correlate these lesions with the variables involved in the process of intubation such as size of endotracheal tube, indication of intubation and the day of extubation.

\section{MATERIAL AND METHODS}

The study was undertaken at the ICU of a Tertiary Care Hospital. Period of study was 02 years from Oct. 2010 to October 2012. Nature of the study was prospective in nature. A total of 100 patients were included in the study. All patients extubated at the intensive care unit of our hospital after at least $24 \mathrm{hrs}$. of intubation were included in the study. Patients who subsequently underwent tracheostomy were excluded from our study.

\section{PROCEDURE}

Written informed consent was obtained from all the subjects or their relatives. The association of laryngeal findings with demographic details along with medical history (Cigarette smoking, COPD, diabetes mellitus and congestive heart failure) and intubation variables [Nature of intubation (Emergency or elective), size of endotracheal tube, skill of intubating personnel (Consultant/Resident) and duration of intubation] were studied. Fibre-optic bronchoscopy was done on day of extubation, and weekly for 03 weeks. On day of extubation, the fibre-optic bronchoscope was passed through the endotracheal tube till just below the tip of the tube. The scope was withdrawn slowly along with the endotracheal tube. Regions which were evaluated in detail included subglottis, vocal cords, arytenoids, AE folds and posterior pharyngeal wall. The followup bronchoscopies were done every week for three weeks either as bedside procedure or on OPD basis depending on the ambulatory and general condition of the patient.

The following grading system was used to document the laryngotracheal alterations.

\begin{tabular}{|l|l|}
\hline Grade 0 & No Change \\
\hline Grade 1 & Erythema and/or Oedema but no Ulceration \\
\hline Grade 2 & $\begin{array}{l}\text { Ulceration and/or Slough but no Narrowing of } \\
\text { Airway }\end{array}$ \\
\hline Grade 3 & $\begin{array}{l}\text { Glottic or Subglottic Narrowing due to Oedema } \\
\text { and/or Slough }\end{array}$ \\
\hline Grade 4 & Vocal Fold Paralysis \\
\hline
\end{tabular}

\section{RESULTS}

Total of 100 patients were included in our study. The demographic data and gender variation did not influence the laryngeal findings on the day of extubation and after 3 weeks. Laryngeal abnormalities were seen in 88 patients on day of extubation ranging from grade 1 to grade 3 . Most common abnormality was vocal cord erythema which presented in approximately $70 \%$ of the patients. Majority of patients; however, gradually recovered and at the end of 03 weeks only 09 patients had residual changes.

Majority of the patients (78\%) underwent elective intubation prior to surgical intervention. $22 \%$ of patients were intubated in view of poor GCS or for maintaining saturation (Table 1). All intubations were done by residents only.

\begin{tabular}{|c|c|c|}
\hline Indication & $\mathbf{N}$ & $\mathbf{\%}$ \\
\hline Not maintaining saturation & 8 & 8 \\
\hline Poor GCS & 13 & 13 \\
\hline Surgery & 76 & 76 \\
\hline Surgery and poor GCS & 2 & 2 \\
\hline Ventilatory support & 1 & 1 \\
\hline Total & $\mathbf{1 0 0}$ & $\mathbf{1 0 0}$ \\
\hline Table 1: Distribution based on the Indication \\
for Intubation \\
\hline
\end{tabular}

\begin{tabular}{|c|c|c|c|c|c|c|c|}
\hline \multirow{4}{*}{$\begin{array}{c}\text { Extubation } \\
\text { Day }\end{array}$} & $\begin{array}{c}\text { Duration of } \\
\text { Intubation }\end{array}$ & $\mathbf{G 0}$ & $\mathbf{G 1}$ & $\mathbf{G 2}$ & $\mathbf{G 3}$ & Total & $\begin{array}{c}\text { P } \\
\text { value }\end{array}$ \\
\cline { 2 - 8 } & 1 & 10 & 30 & 6 & & 46 & \\
\cline { 2 - 7 } & 2 to 4 & 2 & 10 & 24 & 12 & 48 & 0.001 \\
\cline { 2 - 6 } & 5 to 6 & - & - & 3 & 3 & 6 & \\
\cline { 2 - 6 } & Total & $\mathbf{1 2}$ & $\mathbf{4 0}$ & $\mathbf{3 3}$ & $\mathbf{1 5}$ & $\mathbf{1 0 0}$ & \\
\hline $\begin{array}{r}\text { Table 2: Distribution of Laryngeal Complications as } \\
\text { per duration of Intubation on Extubation day }\end{array}$ \\
\hline
\end{tabular}

Majority of patients gradually and spontaneously recovered over the period of 03 weeks. At the end of 03 weeks, only 09 patients had residual changes (Table 3 ).

\begin{tabular}{||c|c|c|c|c|c|c|c|}
\hline \multirow{4}{*}{ Week 3 } & $\begin{array}{l}\text { Duration of } \\
\text { Intubation }\end{array}$ & G0 & G1 & G2 & G3 & Total & $\begin{array}{c}\text { P } \\
\text { value }\end{array}$ \\
\cline { 2 - 8 } & 1 & 46 & - & - & - & 46 & \\
\cline { 2 - 8 } & 2 to 4 & 41 & 1 & 4 & 2 & 48 & 0.017 \\
\cline { 2 - 7 } & 5 to 6 & 4 & 1 & 1 & - & 6 & \\
\cline { 2 - 7 } & Total & $\mathbf{9 1}$ & $\mathbf{2}$ & $\mathbf{5}$ & $\mathbf{2}$ & $\mathbf{1 0 0}$ & \\
\hline
\end{tabular}

Table 3: Distribution of Laryngeal Complications as per duration of Intubation on Week 3

\begin{tabular}{|c|c|c|c|c|c|c|}
\hline \multirow{5}{*}{$\begin{array}{c}\text { Duration of } \\
\text { Intubation } \\
\text { (Days) }\end{array}$} & 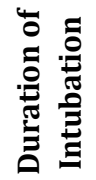 & 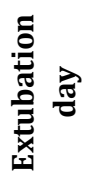 & $\frac{-1}{d}$ & $\frac{N}{d}$ & 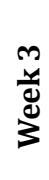 & $\frac{0}{\stackrel{0}{\pi}}$ \\
\hline & 1 & 36 & 34 & 0 & 0 & \multirow{3}{*}{0.01} \\
\hline & 2 to 4 & 46 & 44 & 11 & 7 & \\
\hline & 5 to 6 & 06 & 06 & 2 & 2 & \\
\hline & Total & 88 & 84 & 13 & 09 & \\
\hline
\end{tabular}

Patients with duration of intubation between 24 to 48 hours had the best outcome. Laryngeal changes in all these patients reverted back to normal within 02 weeks. As the duration of intubation increased percentage of permanent sequelae also increased. Duration of intubation was a significant factor in laryngotracheal outcomes (Table 4).

Tube size was found to be a significant factor affecting the outcomes post-intubation. Size 8 tube was more commonly associated with grade 3 changes when compared with size 7.5 and size 7 (Table 5). 


\begin{tabular}{|c|c|c|c|c|c|c|c|}
\hline \multirow{4}{*}{$\begin{array}{c}\text { Extubation } \\
\text { Day }\end{array}$} & $\begin{array}{c}\text { Tube } \\
\text { Size }\end{array}$ & G0 & G1 & G2 & G3 & Total & $\begin{array}{c}\text { P } \\
\text { value }\end{array}$ \\
\cline { 2 - 9 } & 7 & 11 & 7 & 2 & 0 & 20 & \multirow{2}{*}{0.001} \\
\cline { 2 - 9 } & 7.5 & 1 & 26 & 18 & 2 & 47 & 0.04 \\
\cline { 2 - 8 } & 8 & - & 7 & 13 & 13 & 33 & \\
\cline { 2 - 8 } & Total & $\mathbf{1 2}$ & $\mathbf{4 0}$ & $\mathbf{3 3}$ & $\mathbf{1 5}$ & $\mathbf{1 0 0}$ & \\
\hline
\end{tabular}

Table 5: Distribution of Laryngeal Complications as per tube size on Extubation day

Chi square test is applied. $P$ value is significant if $<0.05$

\section{DISCUSSION}

The use of endotracheal intubation for respiratory support of critically ill patients has become a standard life saving therapy. Extensive reports in the literature of the involved medical and surgical specialities have defined the complications which can occur in using this therapeutic modality. Many factors which contributed to an increased incidence of these complications have been defined. With understanding of these factors, extensive improvements have been made in the system design such as the modern high-volume low-pressure cuff. These factors have combined to allow an apparent increased safety of endotracheal intubation for the adult patient population. This has also led to progressive increase in the duration of intubation.

The discrepancy between clinically evident damage and the infrequent patient progressing to stenosis obviously indicates a high degree of spontaneous organ healing. The incidences of these various sequelae have not been consistently or clearly defined particularly in terms of length of continuous intubation.

Total of 100 patients were included in our study. Laryngeal abnormalities were seen in 88 patients on day of extubation ranging from grade 1 to grade 3 (Table 2). Most common abnormality was vocal cord erythema which presented in approximately $70 \%$ of the patients. Majority of patients; however, gradually recovered and at the end of 03 weeks only 09 patients had residual changes (Table 3). Table 4 and 5 shows data regarding intubation variables and their association with the laryngeal sequelae on the day of extubation and after 1, 2 and 3 weeks.

Study shows that tube size (Size 8) was associated with higher incidence of grade 3 changes and also a higher incidence of residual changes after 3 weeks. Univariate analysis of the intubation variables showed larger endotracheal tube size $(\mathrm{P}=0.001)$, and longer duration of intubation $(\mathrm{P}=0.004)$ influenced postextubation laryngeal sequelae. When subjected to statistical multivariate analysis, larger endotracheal tube size $(\mathrm{P}=0.001)$, and prolonged intubation $(\mathrm{P}=0.004)$ were the only significant factors associated with the laryngeal findings on the day of extubation.

Laryngotracheal injuries following intubation have a reported incidence from 63.[6] to $94 \% .^{[4]}$ and permanent sequelae are reported to be about $10 .{ }^{[6]}$ to $22 \% .{ }^{[7]}$ in the world literature. In our study, we found the incidence of injuries following extubation to be $88 \%$ and permanent sequelae to be 09\%. Improvement in cuff design (High-volume low-pressure cuffs) has permitted prolonged ventilation through endotracheal tube. The time to switch over from endotracheal tubes to tracheostomy is controversial. Current data suggest that ventilation through high-volume low-pressure endotracheal tubes are the method of choice of artificial airway up to 3 weeks. ${ }^{[8]}$
The laryngeal injuries can vary from mucosal injuries like vocal cord erythema, oedema, granulations and ulcerations to more permanent sequelae like arytenoids dislocation. ${ }^{[9,10,11]}$, vocal cord palsy.[3,12,13] and subglottic stenosis.[6,12] In our study, vocal cords, arytenoids and subglottic region were the only components of the larynx involved in injuries. There were no patients with vocal cord paralysis, arytenoid dislocations or tracheal and subglottic stenosis in this study population. Risk factors like smoking.[14], diabetes mellitus.[15], COPD, congestive heart failure.[15] were not associated with the laryngeal sequelae as reported in the literature.

The comorbidities would have probably influenced the duration of intubation indirectly but they did not seem to have any direct influence on the presence of laryngeal complications. Chronic obstructive pulmonary disease and smoking, though expected to contribute to the presence of laryngeal injuries, did not do so in our study. The female gender is expected to be more prone to laryngeal injuries due to the smaller size of their larynges. An earlier retrospective study.[16] of 304 patients by Rajagopalan et al[16] had shown female gender to be a significant predictor of post-extubation stridor $(\mathrm{P}=0.0003)$. However, in our study, laryngeal sequelae were not associated with gender.

Cuff pressure is an important factor for assessing laryngotracheal injuries. However, in our study, we did not evaluate this factor as cuff pressure is routinely monitored by the ICU staff in our hospital by palpatory method and changed time to time. The use of high-volume low-pressure endotracheal tubes are also a routine practice in our intensive care unit. These tubes have a cuff with a large resting volume and diameter and a thin compliant wall that allows a seal with the trachea to be achieved without stretching its wall. This reduces the risk of injury to tracheal tissues, thereby reducing the risk of significant cuff-induced complications following prolonged intubation. The skill of the intubating physician also plays an important role in the genesis of laryngeal injuries. As per literature, the residents and trainees with less skill and experience have comparatively greater association with complications than the consultants. However, we could not assess this factor in our study as all the intubations were done by residents only.

Use of high-volume low-pressure cuffs and regular monitoring of cuff pressures seems to decrease the laryngeal injuries secondary to prolonged intubation. Use of appropriate tube size and monitoring of duration of intubation is of paramount importance. A systematic laryngeal examination after extubation, whenever indicated, decreases the secondary sequelae by initiating appropriate measures when necessary.

The small number of patients as well as the decision to exclude patients, who underwent tracheostomy, limits our study. It is possible that many patients underwent tracheostomy due to laryngeal lesions and were not represented in the study. At the same time whether early tracheostomy was justified in these patients needs further consideration. As per our study, it is recommended to use smaller size tube in cases where prolonged intubation is anticipated.

Large multicentre studies with bigger cohorts are needed to definitely establish the role of medical disorders and other parameters in producing laryngeal complications in patients with prolonged intubation. 


\section{REFERENCES}

1. Martins RHG, Dias NH, Braz JRC, et al. Complicações das vias aéreas relacionadas à intubação endotraqueal. Rev Bras Otorrinolaringol 2004;70(5):671-7.

2. Lindholm CE. Prolonged endotracheal intubation. Acta Anaesthesiol Scand Suppl 1970;33:1-131.

3. Santos PM, Afrassiabi A, Weymuller EA. Risk factors associated with prolonged intubation and laryngeal injury. Otolaryngol Head Neck Surg 1994;111(4):453-9.

4. Woo P, Kelly G, Kirshner P. Airway complications in the head injured. Laryngoscope 1989;99(7 Pt 1):725-31.

5. Lindholm CE. Prolonged endotracheal intubation. A clinical investigation with special reference to its consequences for the larynx and trachea and to its place an alternative to intubation through a tracheostomy. Acta Anaesthesiol Scand 1969;33:1-131.

6. Kastanos N, Miro ER, Perez MA, et al. Laryngotracheal injury due to endotracheal intubation: incidence, evolution, and predisposing factors. A prospective longterm study. Crit Care Med 1983;11(5):362-7.

7. Colice GL. Resolution of laryngeal injury following translaryngeal intubation. Am Rev Respir Dis 1992;145(2Pt 1):361-4.

8. Hsu CL, Chen KY, Chang CH, et al. Timing of tracheostomy as a determinant of weaning success in critically ill patients: a retrospective study. Crit Care 2005;9(1): R46-52.
9. Rudert H. Uncommon injuries of the larynx following intubation. Recurrent paralysis, torsion and luxation of the cricoarytenoid joints. HNO 1984;32(9):393-8.

10. Rieger A, Hass I, Gross M, et al. Intubation trauma of the larynx: a literature review with special reference to arytenoid cartilage dislocations. Anasthesiol Intensivmed Notfallmed Schmerzther 1996;31(5):281-7.

11. Obrebowski A, Wojnowski W. Hoarseness resulting from post-intubation arytenoid cartilage subluxation in an 11year-old girl. Otolaryngol Pol 1998;52(2):223-6.

12. Lundy DS, Casiano RR, Shatz D, et al. Laryngeal injuries after long-term intubation. J Voice 1998;12(3):360-5.

13. Panda NK, Mann SB, Raja BA, et al. Fibreoptic assessment of post intubation laryngotracheal injuries. Indian J Chest Dis Allied Sci 1996;38(4):241-7.

14. Ellis SF, Pollak AC, Hanson DG, et al. Videolaryngoscopic evaluation of laryngeal intubation injury: incidence and predictive factors. Otolaryngol Head Neck Surg 1996;114(6):729-31.

15. Volpi D, Lin PT, Kuriloff DB, et al. Risk factors for intubation injury of the larynx. Annal Otol Rhinol Laryngol 1987;96(6):684-6.

16. Rajagopalan R, Rajaram R, Pai M, et al. Incidence and risk factors of post-extubation stridor in a cohort of adult intensive care patients in South India (abstract). Indian J Crit Care Med 1999;3:75-6. 